\title{
repisälud
}

This is the peer reviewed version of the following article:

Rossello X, Pinero A, Fernandez-Jimenez R, Sanchez-Gonzalez J, Pizarro G, Galan-Arriola C, Lobo-Gonzalez M, Vilchez JP, Garcia-Prieto J, Garcia-Ruiz JM, Garcia-Alvarez A, Sanz-Rosa D, Ibanez B. Mirabegron, a Clinically Approved beta3 Adrenergic Receptor Agonist, Does Not Reduce Infarct Size in a Swine Model of Reperfused Myocardial Infarction. J Cardiovasc Trans/ Res, 2018. 11(4): p. 310-318.

which has been published in final form at: https://doi.org/10.1007/s12265-018-9819-8 


\section{Mirabegron, a clinically approved $\beta 3$ adrenergic receptor agonist, does not reduce infarct size in a swine model of reperfused myocardial infarction}

Short title: Mirabegron in a swine model of I/R injury

Xavier Rossello ${ }^{1,2}, \mathrm{MD}, \mathrm{PhD}$, Antonio Piñero ${ }^{2,3}, \mathrm{MD}, \mathrm{PhD}$, Rodrigo FernándezJiménez ${ }^{1,2,4}, \mathrm{MD}, \mathrm{PhD}$, Javier Sánchez-González ${ }^{5}, \mathrm{PhD}$, Gonzalo Pizarro ${ }^{1,2,6}, \mathrm{MD}, \mathrm{PhD}$, Carlos Galán-Arriola ${ }^{1,2}$, DVM, Manuel Lobo-Gonzalez ${ }^{1,2}$, MD, Jean Paul Vilchez ${ }^{1,2}$, MD, Jaime García-Prieto ${ }^{1,2}$, PhD, Jose Manuel García-Ruiz ${ }^{1,2}$, MD, Ana GarciaAlvarez $^{1,2}, \mathrm{MD}, \mathrm{PhD}$, David Sanz-Rosa ${ }^{1,2,6}, \mathrm{PhD}$, Borja Ibanez ${ }^{1,2,3}, \mathrm{MD}, \mathrm{PhD}$

${ }^{1}$ Centro Nacional de Investigaciones Cardiovasculares Carlos III (CNIC), Madrid, Spain

${ }^{2}$ CIBER de enfermedades CardioVasculares (CIBERCV), Madrid, Spain

${ }^{3}$ Cardiology Department, IIS-Fundación Jiménez Díaz Hospital, Madrid

${ }^{4}$ The Zena and Michael A. Wiener Cardiovascular Institute, Icahn School of Medicine at Mount Sinai, New York, USA

${ }^{5}$ Philips Healthcare, Madrid, Spain

${ }^{6}$ Department of Medicine, Faculty of Biomedical and Health Sciences., Universidad Europea, Madrid, Spain

Total word count: 5913

\section{Address for correspondence:}

Dr. Borja Ibáñez,

Translational Laboratory for Cardiovascular Imaging and Therapy,

Centro Nacional de Investigaciones Cardiovasculares Carlos III (CNIC),

Melchor Fernández Almagro, 3, 28029, Madrid, Spain.

Email: bibanez@cnic.es 


$\begin{array}{ll}\text { Abbreviations } & \\ \text { AMI } & \text { acute myocardial infarction } \\ \beta 3 A R & \beta 3 \text { adrenergic receptor } \\ \text { CMR } & \text { cardiovascular magnetic resonance } \\ \text { IRI } & \text { ischemia/reperfusion injury } \\ \text { IS } & \text { infarct size } \\ \text { LV } & \text { left ventricle } \\ \text { LVEDV } & \text { left ventricular end-diastolic volume } \\ \text { LVEF } & \text { left ventricular ejection fraction } \\ \text { LVESV } & \text { left ventricular end-systolic volume } \\ \text { NOS } & \text { nitric oxide synthase }\end{array}$




\begin{abstract}
The administration of the selective $\beta 3$ adrenergic-receptor ( $\beta 3 \mathrm{AR}$ ) agonist BRL-37344 protects from myocardial ischemia/reperfusion injury (IRI), although the lack of clinical approval limits its translatability. We tested the cardioprotective effect of mirabegron, the first-in-class $\beta 3 \mathrm{AR}$ agonist approved for human use. A dose-response study was conducted in 6 pigs to select the highest intravenous dose of mirabegron without significant detrimental hemodynamic effect. Subsequently, closed-chest anterior myocardial infarction (45min ischemia followed by reperfusion) was performed in 26 pigs which randomly received either mirabegron $(10 \mu \mathrm{g} / \mathrm{kg})$ or placebo 5min before reperfusion. Day-7 cardiac magnetic resonance (CMR) showed no differences in infarct size $(35.0 \pm 2.0 \%$ of left ventricle (LV) vs. $35.9 \pm 2.4 \%$ in mirabegron and placebo respectively, $\mathrm{p}=0.782)$ or $\mathrm{LV}$ ejection fraction $(36.3 \pm 1.1 \%$ vs. $34.6 \pm 1.9 \%, \mathrm{p}=0.430)$. Consistent results were obtained on day-45 CMR. In conclusion, the intravenous administration of the clinically available selective $\beta 3 \mathrm{AR}$ agonist mirabegron does not reduce infarct size in a swine model of IRI.
\end{abstract}

Key words: cardioprotection; $\beta 3$ adrenergic receptor; ischemia/reperfusion injury; acute myocardial infarction; translational models; mirabegron 


\section{Introduction}

Acute myocardial infarction (AMI) is a leading cause of mortality and morbidity worldwide [1,2]. Early coronary reperfusion limits myocardial infarct size (IS), which is the main prognostic determinant in post-AMI patients [3]. Paradoxically, reperfusion itself induces additional damage to the myocardium, known as ischemia/reperfusion injury (IRI) [4]. Beyond timely reperfusion, further IS-limiting therapies targeting the myocardial injury that occurs after ischemia/reperfusion are needed to further improve clinical outcomes [5].

The $\beta 3$ adrenergic-receptor ( $\beta 3 \mathrm{AR})$ is a G-protein-coupled receptor preferentially expressed in adipose tissue that has been raising interest as a cardiovascular target due to its expression in human cardiomyocytes and endothelial cells[6], as well as its protective role in several cardiovascular diseases [7]. The administration of the $\beta 3$ AR agonist BRL-37344 either 5 min before or at the onset of reperfusion, has been demonstrated to reduce myocardial IS and improve cardiac function both in mouse [8, 9] and swine models of IRI [9]. Also, $\beta 3 \mathrm{AR}$ stimulation has been shown to improve left ventricular (LV) remodeling in small animal models of heart failure after non-reperfused MI [10] or pressure overload hypertrophy [11], as well as to improve right ventricular performance in a porcine model of chronic pulmonary hypertension [12]. Many of these protective effects are mediated through the nitric oxide synthase (NOS), as $\beta 3 \mathrm{AR}$ effects are abrogated with either its pharmacological or genetic inhibition $[9,13]$.

The $\beta 3 \mathrm{AR}$ agonist (mirabegron) is the first agent of this class clinically approved (in Europe, US and Japan) for treating overactive bladder [14]. However, there is no data regarding its potential benefit in the context of AMI, based on the principle of "drug repurposing" for a new cardiovascular indication. Confirmation of an infarct-limiting effect and long-term functional benefits from this new therapeutic strategy in a large animal model would have a significant translational impact and should be considered the first step before conducting a clinical trial in humans in this setting [15].

We therefore hypothesized that the $\beta 3 \mathrm{AR}$ agonist mirabegron may provide a protective effect against myocardial IRI, improving both IS and LV function and remodeling. According to 
this hypothesis, the aims of this study were (1) to assess the effect of the administration of mirabegron on hemodynamic parameters in a dose-response fashion and determine the optimal intravenous dose to use in subsequent experiments; (2) to investigate whether $\beta 3$ stimulation with mirabegron reduces myocardial IS in a large animal model of IRI; and (3) to elucidate whether $\beta 3$ stimulation with mirabegron improves ventricular remodelling and left ventricular ejection fraction (LVEF) in a large animal model of AMI.

\section{Methods}

Animals and drug

All animal studies were conducted at the CNIC and approved by the local CNIC Institutional Animal Research Committee, and the Regional Animal Research Committee. All animal procedures conformed to EU Directive 2010/63EU and Recommendation 2007/526/EC regarding the protection of animals used for experimental and other scientific purposes. Pharmocokinetics and bioavalability of mirabegron in healthy subjects and animals has been described elsewhere [16, 17].

\section{$\underline{\text { Study design }}$}

The study design consisted of two stages, the first to identify the best dose of mirabegron, and the second one to assess its cardioprotective effects. In phase one, we performed a dose-response evaluation aimed to determine the optimal intravenous dose to be uses subsequently in phase two. Four intravenous bolus doses of mirabegron $(5,10,50$ and 500 $\mu \mathrm{g} / \mathrm{Kg}$ ) were administered alongside its vehicle ( $1 \mathrm{ml} \mathrm{DMSO}+19 \mathrm{ml}$ of saline) in a group of six healthy pigs under close monitoring through electrocardiogram, pulse oximeter, invasive systemic blood pressure (SBP) and right heart catheterization. A complete hemodynamic evaluation was obtained every minute during the first $5 \mathrm{~min}$ and then every 5 min until reaching 20 min post-drug administration. The highest dose with no significant detrimental hemodynamic effects was chosen. No significant detrimental effect was defined as changes in hemodynamics of less than $10 \%$ with respect the baseline value. 
In phase two, 26 pigs undergoing IRI (45 minutes coronary artery occlusion followed by reperfusion) were randomized to either receive a bolus of intravenous placebo ( $1 \mathrm{ml}$ of DMSO $+19 \mathrm{ml}$ of saline $)$ or intravenous mirabegron $(10 \mu \mathrm{g} / \mathrm{kg}$ diluted in $1 \mathrm{ml}$ of DMSO +19 $\mathrm{ml}$ of saline) over a 30 seconds period at min 40 of ischemia (i.e. 5 minutes prior to reperfusion). Cardiac magnetic resonance (CMR) was performed at two time-points: a) day 7; and b) day 45 , after reperfusion. The pre-defined primary endpoint of the study was IS (\% LV mass) on day 7 CMR, while the main secondary endpoint was LVEF on day 45 CMR.

Pig model of acute myocardial infarction

AMI was experimentally induced in 3-month-old castrated male Large-white pigs bred at the CNIC's farm. The protocol for AMI induction has been described in detail elsewhere[18]. Briefly, anesthesia was induced by intramuscular injection of ketamine $(20 \mathrm{mg} / \mathrm{kg})$, xylazine (2 $\mathrm{mg} / \mathrm{kg})$, and midazolam $(0.5 \mathrm{mg} / \mathrm{kg})$, and maintained by continuous intravenous infusion of ketamine $(2 \mathrm{mg} / \mathrm{kg} / \mathrm{h})$, xylazine $(0.2 \mathrm{mg} / \mathrm{kg} / \mathrm{h})$, and midazolam $(0.2 \mathrm{mg} / \mathrm{kg} / \mathrm{h})$. The analgesic buprenorphine $(0.03 \mathrm{mg} / \mathrm{kg})$ was administered by intramuscular injection immediately before the procedure.

Pigs were intubated and mechanically ventilated with oxygen (fraction of inspired $\mathrm{O}_{2}$, 28\%). Central venous and arterial lines were inserted, and a single bolus of unfractionated heparin (300 IU $/ \mathrm{kg}$ ) was administered at the onset of the instrumentation. During the procedure, a continuous infusion of amiodarone $(300 \mathrm{mg} / \mathrm{h})$ was systematically used to avoid malignant ventricular arrhythmias. Amiodarone was initiated immediately after coronary artery occlusion. The mid-left anterior descending coronary artery (distal to the origin of the first diagonal branch) was occluded for 45 min with an angioplasty balloon inserted through percutaneous femoral access. After $45 \mathrm{~min}$, the balloon was deflated, and blood flow restoration was documented by angiography. Animals were randomly allocated 1:1 to receive either the b3AR agonist (mirabegron, $10 \mu \mathrm{g} / \mathrm{kg}$ ) or vehicle via marginal vein of the ear $5 \mathrm{~min}$ before reperfusion (i.e. 40 min after coronary artery occlusion). The treatment (mirabegron or vehicle) was 
administered by operators blinded to the allocation. During the procedure, invasive hemodynamic measurements were obtained as detailed above. After the procedure, both veterinarians and technicians at the CNIC Comparative Medicine Unit took care of the recovery of the animals.

\section{CMR protocol}

CMR studies were performed 7 and 45 days after AMI to assess infarct size (\% of LV) and LV function. On each CMR exam, pigs were anesthetized by intramuscular injection of ketamine, xylazine and midazolam as described above, and maintained by continuous intravenous infusion of midazolam. All studies were performed using a Philips Achieva 3T-Tx whole body scanner (Philips Medical Systems, Best, The Netherlands) equipped with a 32element cardiac phased-array surface coil. Images were acquired with the use of electrocardiogram gating by operators blinded to the treatment allocation. Segmented cine steady-state free precession (SSFP) was performed to acquire 15 contiguous short-axis slices covering the heart from the base to the apex to assess LV mass, LV volumes and ejection fraction with the following parameters: FOV of 280 x $280 \mathrm{~mm}$; slice thickness of $6 \mathrm{~mm}$ without gap; TR 2.8 ms; TE 1.4 ms, flip angle 45; cardiac phases 25; voxel size 1.8 x 1.8 mm; 3 NEX. Edema imaging was performed using a T2-weighted, triple inversion-recovery fast spin-echo (T2W-STIR) sequence with the following parameters: FOV of $300 \times 300 ; 15$ short-axis slices with thickness of $6 \mathrm{~mm}$ and no gap; TR 2 heartbeats; TE $80 \mathrm{~ms}$; voxel size 1.4 x $1.8 \mathrm{~mm}$; STIR delay 210 ms; echo-train length 18; 2 NEX. T2W images were corrected by coil sensitivities using Constant LEvel AppeaRance (CLEAR) algorithm. To determine myocardial IS, late gadolinium enhancement imaging was performed 15 min after the administration of 0.2 $\mathrm{mmol} / \mathrm{kg}$ gadopentate dimeglumine using a $\mathrm{T} 1$ inversion-recovery spoiled turbo field echo (T1IR-TFE) sequence with the following parameters: FOV of 280 x $280 \mathrm{~mm}$; 15 short axis slices with a thickness of $6 \mathrm{~mm}$ and no gap; TR $3.3 \mathrm{~ms}$; TE $1.6 \mathrm{~ms}$; voxel size 1.8 x $1.8 \mathrm{~mm}$; inversion time was optimized to null normal myocardium; 2 NEX. 


\section{$\underline{\text { CMR data analysis }}$}

All CMR images were assessed using dedicated software (QMassMRv.7.6, Medis, Leiden, The Netherlands). Images were evaluated by 2 experienced observers in CMR analysis, blinded to treatment allocation, following a well-established protocol as described previously[9]. Briefly, LV cardiac borders were traced in each cine image to obtain LV enddiastolic mass, LV end-diastolic volume (LVEDV), end-systolic volume (LVESV) and LVEF. LV mass and volumes normalized to the body surface area were calculated using the modified Brody's method[19]. The extent of edema, expressed as a percentage of LV mass, was defined after manually tracing the endocardial and epicardial contours of T2W-STIR short-axis images. IS, expressed as a percentage of LV mass, was defined according the extent of late gadolinium enhancement after manually tracing the endocardial and epicardial contours on T1-IR-TFE short axis images. Edema and IS were identified as hyperintense regions, defined as $>50 \%$ of the peak myocardial signal intensity (full width half maximum) with manual adjustment if required. When present, hypointense areas within the edematous or necrotic zone were included in the edematous or necrotic region for quantification purposes.

$\underline{\text { Statistical analysis }}$

Continuous variables are expressed as mean \pm standard deviation. Levene's robust test was performed to check the equality of variances between groups. CMR outcomes were compared between treatment groups using the Student's t-test. A generalized mixed model was conducted for comparison of heart rate and mean arterial pressure among repeated measures at different time points. All pairwise comparisons were explored, adjusting $\mathrm{p}$ values for multiple comparisons using the Bonferroni method. A P value of less than 0.05 was considered statistically significant. STATA software, version 15.1 (Stata Corp, College Station, TX, USA) was used throughout. 


\section{Results}

\section{Phase 1: Dose-response study}

To select the highest dose without a relevant (detrimental) hemodynamic effect $(<10 \%$ change in mean systemic blood pressure or heart rate), a dose-response assessment was performed in anesthetized pigs using the following doses $5,10,50$ and $500 \mu \mathrm{g} / \mathrm{Kg}$. The effect of intravenous administration of mirabegron on relevant hemodynamic parameters is presented in Table 1. Overall, the two low doses ( 5 and $10 \mu \mathrm{g} / \mathrm{Kg}$ ) had little impact on the hemodynamic performance, whilst the two high doses (50 and $500 \mu \mathrm{g} / \mathrm{Kg}$ ) resulted in a substantial impact on both cardiac output and heart rate. Taking into account these results, a dose of $10 \mu \mathrm{g} / \mathrm{Kg}$ was chosen for subsequent experiments.

\section{Phase 2: Effect of mirabegron in IRI}

$\underline{\text { Study population }}$

Twenty-six pigs underwent AMI procedure. One AMI procedure failed, and 5 pigs died within the first week after AMI before day7 CMR ( 3 allocated to placebo and 2 allocated to mirabegron). Thus, a total of 20 pigs ( $n=10 /$ group) underwent CMR at day 7 having the primary outcome measured and comprised the final study population. Two of these 20 pigs died between day 7 and 45, both belonging to the mirabegron group. During AMI procedure, there were no relevant differences in hemodynamic parameters between placebo pigs and those allocated to mirabegron (Table 2).

\section{$\underline{\mathrm{CMR} \text { at day } 7}$}

CMR results at day 7 after AMI by group allocation are detailed in Table 3. At this time-point, there were no significant differences in neither infarct size (35.0 $\pm 2.0 \%$ vs. $35.9 \pm 2.4 \%$ in mirabegron and placebo respectively, $\mathrm{p}=0.782)$ nor in LVEF ( $36.3 \pm 1.1 \%$ vs. $34.6 \pm 1.9 \%$, respectively; $\mathrm{p}=0.430$ ) (Figure 1). Similarly, there were no differences in the extension of edema as measured by T2W-STIR between groups $(38.0 \pm 5.6 \%$ of LV vs. $38.4 \pm$ $5.9 \%$ of $\mathrm{LV}$, in mirabegron and placebo respectively; $\mathrm{p}=0.884)$. The presence of microvascular 
obstruction was not different between groups $(2.3 \pm 1.6 \mathrm{~g}$ vs $2.1 \pm 1.9 \mathrm{~g}$, in mirabegron and placebo respectively; $\mathrm{p}=0.841$ ).

\section{$\underline{\text { CMR at day } 45}$}

Consistent results were obtained after 45 days of reperfusion (Table 4). No significant differences were observed between groups in neither IS $(23.7 \pm 6.3 \%$ vs $25.2 \pm 4.5 \%$, in mirabegron and placebo, respectively; $\mathrm{p}=0.581)$ nor in LVEF $(33.1 \pm 5.7 \%$ vs. $30.0 \pm 7.0 \%$, respectively; $\mathrm{p}=0.366$ ) (Figure 2). No significant differences were observed in LV end-diastolic volume $\left(189.6 \pm 23.7 \mathrm{ml} / \mathrm{m}^{2}\right.$ vs. $202.9 \pm 43.4 \mathrm{ml} / \mathrm{m}^{2}$ in mirabegron and placebo respectively; $\mathrm{p}=0.449)$ and end-systolic volume $\left(127.9 \pm 26.7 \mathrm{ml} / \mathrm{m}^{2}\right.$ vs. $143.9 \pm 43.5 \mathrm{ml} / \mathrm{m}^{2}$ in mirabegron and placebo respectively; $\mathrm{p}=0.377$ ).

\section{Discussion}

$\beta 3 \mathrm{AR}$ stimulation with mirabegron does not protect the myocardium against IRI in a swine model of AMI. To our knowledge, this is the first study demonstrating that the i.v. administration of mirabegron fails to confer cardioprotection in a large animal model of IRI. Given the previous demonstration of the infarct-limiting effects of other $\beta 3 \mathrm{AR}$ agonists $[8,9]$, our data suggest a non-class infarct limiting effect of $\beta 3$ AR agonism.

There is a wealth of evidence demonstrating the cardioprotective effect afforded by $\beta 3 \mathrm{AR}$ agonists when administered during the first minutes of reperfusion $[8,9]$. It has been suggested that this cardioprotective effect is provided (i) at the myocardial level by a delay in mPTP opening dependent on the Akt-NO signaling pathway; and (ii) at the endothelial level by the release of NO. These protective effects at the myocardial and endothelial level may be reinforced from other effects - i.e. paracrine effect of $\mathrm{NO}$ to improve LV relaxation and antioxidant effects of $\beta 3 \mathrm{AR}$ signaling, which may help to preserve microvasculature [7]. However, all this previous evidence was based on the $\beta 3$ AR agonist BRL-37344 $[8,9]$. 
Unexpectedly, the administration of mirabegron did not confer protection against IRI in our swine model of AMI. This seemingly contradictory results do not necessarily contravene previous reports and might be explained by several reasons.

The most important difference with previous reports lies in the use of different drugs. Within high-affinity $\beta 3$ AR agonists, BRL37344 belongs to the phenylethanolamines class and mirabegron (YM178) belongs to the aryloxypropanolamines [12]. The latter has the advantage of being already approved for human use to treat hyperactive bladder syndrome as well as being available in oral tablets [14], which might be useful as a longer treatment to improve post-AMI LV remodeling and LVEF [20]. It is known that BRL37344 has a lower affinity for $\beta 3 \mathrm{AR}$ in comparison with mirabegron [21]. Similarly, BRL37344 has a slight effect in other $\beta$ AR [22], which might justify the disagreement in our results. However, BRL37344 did not confer cardioprotection in $\beta 3 \mathrm{AR} \mathrm{KO}$ mice [9], thus suggesting a minor role for other $\beta$ adrenergic receptors.

The second possibility justifying the failed study is the dose of the drug used in the IRI experiments. Given the lack of publications in this regard, we chose the mirabegron dose based on our hemodynamic assessment. Higher doses of mirabegron provided substantial change in cardiac output as well as transitorily reduction in systolic blood pressure, although we lack information regarding the hemodynamic response in the range of 10 to $50 \mu \mathrm{g} / \mathrm{Kg}$, which might be of interest considering our results. Prior studies in animal models of cardiovascular disease have reported the use of either oral [12] or i.v. mirabegron [16, 23, 24], although the latter were performed mostly in rats. It might be possible that the appropriate dose was not used. Another explanation might be the already known interspecies differences in the cardiac effects of $\beta 3 \mathrm{AR}$ agonists [25] - i.e. mirabegron showed less cardiovascular effects in monkeys than in dogs at similar exposures [17], although little has been published before regarding the effect of $\beta 3 \mathrm{AR}$ agonism in pigs [9].

There is yet a third potential explanation. Although $\beta 3 \mathrm{AR}$ agonists have been demonstrated to protect the heart against IRI when administered either immediately before or at 
the onset of reperfusion $[8,9]$, it might be possible that this single dose of mirabegron was not enough time "on board". Recent experimental studies have demonstrated the importance of the contribution of ischemic-related injury on top of reperfusion-related injury [26-28]. Moreover, some therapies, such as metoprolol [29] and remote ischemic conditioning [30], have demonstrated to be more effective when applied long before reperfusion in the clinical setting. These recent findings place ischemic injury back into the focus of relevant targets for IS reduction and suggest that next cardioprotective therapies should be tested long before reperfusion and not only 5 min before its onset, as we did in the present study.

There is yet hope for the translation of mirabegron in cardiovascular diseases. Despite the fact that we did not find significant differences on IS reduction and LVEF improvement after the use of mirabegron at the dose studied, further research testing the cardioprotective effect of mirabegron (or other $\beta 3 \mathrm{AR}$ agonists) at different doses and earlier in the course of ischemic time is needed in similar translational models to elucidate the potential applicability of this therapy in the clinical setting. Moreover, there might still be room for its translation in the failing heart in form of chronic treatment $[11,13,20]$ - several clinical trials are currently recruiting patients to test the performance of mirabegron in both LV and RV failing hearts. There is a phase IIb, international ( 8 countries), placebo-controlled randomized trial (ISRCTN65055502) testing the effect of mirabegron to prevent or reverse the LV hypertrophic remodeling of patients with structural heart disease who are at risk of developing HF with preserved ejection fraction. The Beta3 Agonist Treatment in Chronic Pulmonary Hypertension Secondary to Heart Failure (SPHERE-HF, NCT02775539) is evaluating whether the use of oral mirabegron would improve surrogate endpoints in patients with pulmonary hypertension associated to heart failure.

\section{$\underline{\text { Limitations }}$}

This study should be evaluated in the light of its limitations. First, although $\beta 3 \mathrm{AR}$ has been demonstrated to be present in the myocardium and endothelium of mammals[7, 17, 25], we did not provide evidence of their existence in our experimental model. Second, the effect of 
mirabegron on other receptors ( $\beta 1 \mathrm{AR}$ and $\beta 2 \mathrm{AR}$ ) was not assessed in this study. Third, other non-pharmacological approaches might be used to confirm our findings, such as enhancing $\beta 3 \mathrm{AR}$ [13]. Further doses of mirabegron and different timings of administration should be tested to confirm that mirabegron has not the ability to be translated to AMI patients. Finally, we cannot ruled-out a bias in relation to the day selected for CMR imaging in the acute phase. In this regard, previous studies have suggested a rapid resorption of late gadolinium enhanced myocardium, as surrogate of IS, over the course of the first week after AMI [31-33].

Additionally, edema formation after IRI is very dynamic [18, 34]; and CMR estimates can vary according to the day of imaging or the use of cardioprotective therapies [32, 35]. However, given that all animals underwent the index CMR exam the same day post-IRI (i.e., day 7), which it is actually within the suggested time window for assessing imaging outcomes [32, 35], we think any potential bias would have affected all groups equally and thus did not have an impact on the results.

\section{Conclusions}

$\beta 3 \mathrm{AR}$ stimulation with the clinically approved mirabegron does not protect the myocardium against IRI in a swine model of AMI. Using cardiovascular magnetic resonance at days 7 and 45, no significant differences in neither infarct size nor in LVEF were observed between mirabegron $(10 \mu \mathrm{g} / \mathrm{kg})$ and placebo when administered $5 \mathrm{~min}$ before reperfusion. Taking into account previous evidence with BRL37344, these data points towards a non-class infarct limiting effect of $\beta 3 \mathrm{AR}$ agonists. 


\section{Acknowledgments}

The authors are greatly indebted to Gonzalo J Lopez-Martin and Angel Macias for image acquisition. The authors thank Tamara Cordoba, Oscar Sanz, Ruben Mota, Santiago Rodriguez, Eugenio Fernández, and the rest of the team at the CNIC Animal Facility and farm for providing outstanding animal care and support. The authors also thank Juan Pellico for the mirabegron purity check out with NMR.

\section{Compliance with Ethical standards}

\section{$\underline{\text { Disclosures }}$}

Dr. Ibanez, and Dr. García-Álvarez are inventors of the patent entitled "Use of selective beta-3 adrenergic agonists for the treatment of pulmonary hypertension"' (PCT/ES2013/ 070611). Javier Sánchez-González is Philips employee.

\section{$\underline{\text { Human subjects }}$}

No human studies were carried out by the authors for this article.

\section{$\underline{\text { Animal studies }}$}

All institutional and national guidelines for the care and use of laboratory animals were followed and approved by the appropriate institutional committees.

\section{Sources of funding}

Dr Rossello has received support from SEC-CNIC CARDIOJOVEN Program. R. F-J is a recipient of funding from the European Union's Horizon 2020 research and innovation program under grant agreement No MSCA-IF-GF-707642. This study was partially supported by grants from the Spanish Ministry of Economy and Competitiveness (MINECO) through the Carlos III Institute of Health-Fondo de Investigación Sanitaria (PI10/02268, PI13/01979, and PI16/02110), and the Fondo Europeo de Desarrolo Regional (FEDER, RD: SAF2013-49663- 
EXP). This study forms part of a Master Research Agreement between the CNIC and Philips Healthcare. The CNIC is supported by the MEIC and the Pro CNIC Foundation, and is a Severo Ochoa Center of Excellence (MEIC award SEV-2015-0505). 


\section{References}

1. Rosselló, X., Huo, Y., Pocock, S., Van de Werf, F., Chin, C. T., Danchin, N., ... Bueno, H. (2017). Global geographical variations in ST-segment elevation myocardial infarction management and post-discharge mortality. International Journal of Cardiology, 245, 27-34. doi:10.1016/j.ijcard.2017.07.039

2. Townsend, N., Wilson, L., Bhatnagar, P., Wickramasinghe, K., Rayner, M., \& Nichols, M. (2016). Cardiovascular disease in Europe: epidemiological update 2016. European Heart Journal, 37(42), 3232-3245. doi:10.1093/eurheartj/ehw334

3. Stone, G. W., Selker, H. P., Thiele, H., Patel, M. R., Udelson, J. E., Ohman, E. M., ... Ben-Yehuda, O. (2016). Relationship Between Infarct Size and Outcomes Following Primary PCI: Patient-Level Analysis From 10 Randomized Trials. Journal of the American College of Cardiology, 67(14), 1674-83. doi:10.1016/j.jacc.2016.01.069

4. Ibáñez, B., Heusch, G., Ovize, M., \& Van de Werf, F. (2015). Evolving Therapies for Myocardial Ischemia/Reperfusion Injury. Journal of the American College of Cardiology, 65(14), 1454-1471. doi:10.1016/j.jacc.2015.02.032

5. Fuster, V. (2014). Top 10 cardiovascular therapies and interventions for the next decade. Nature reviews. Cardiology, 11(11), 671-83. doi:10.1038/nrcardio.2014.137

6. Gauthier, C., Tavernier, G., Charpentier, F., Langin, D., \& Le Marec, H. (1996). Functional beta3-adrenoceptor in the human heart. The Journal of clinical investigation, 98(2), 556-62. doi:10.1172/JCI118823

7. Balligand, J.-L. (2016). Cardiac salvage by tweaking with beta-3-adrenergic receptors. Cardiovascular research, 111(2), 128-33. doi:10.1093/cvr/cvw056

8. Aragón, J. P., Condit, M. E., Bhushan, S., Predmore, B. L., Patel, S. S., Grinsfelder, D. B., ... Lefer, D. J. (2011). Beta3-adrenoreceptor stimulation ameliorates myocardial ischemia-reperfusion injury via endothelial nitric oxide synthase and neuronal nitric oxide synthase activation. Journal of the American College of Cardiology, 58(25), 2683- 
91. doi:10.1016/j.jacc.2011.09.033

9. García-Prieto, J., García-Ruiz, J. M., Sanz-Rosa, D., Pun, A., García-Alvarez, A., Davidson, S. M., ... Ibanez, B. (2014). $\beta 3$ adrenergic receptor selective stimulation during ischemia/reperfusion improves cardiac function in translational models through inhibition of mPTP opening in cardiomyocytes. Basic research in cardiology, 109(4), 422. doi:10.1007/s00395-014-0422-0

10. Niu, X., Zhao, L., Li, X., Xue, Y., Wang, B., Lv, Z., ... Zheng, Q. (2014). ß3Adrenoreceptor stimulation protects against myocardial infarction injury via eNOS and nNOS activation. PloS one, 9(6), e98713. doi:10.1371/journal.pone.0098713

11. Niu, X., Watts, V. L., Cingolani, O. H., Sivakumaran, V., Leyton-Mange, J. S., Ellis, C. L., ... Barouch, L. A. (2012). Cardioprotective effect of beta-3 adrenergic receptor agonism: role of neuronal nitric oxide synthase. Journal of the American College of Cardiology, 59(22), 1979-87. doi:10.1016/j.jacc.2011.12.046

12. García-Álvarez, A., Pereda, D., García-Lunar, I., Sanz-Rosa, D., Fernández-Jiménez, R., García-Prieto, J., ... Ibañez, B. (2016). Beta-3 adrenergic agonists reduce pulmonary vascular resistance and improve right ventricular performance in a porcine model of chronic pulmonary hypertension. Basic research in cardiology, 111(4), 49. doi:10.1007/s00395-016-0567-0

13. Belge, C., Hammond, J., Dubois-Deruy, E., Manoury, B., Hamelet, J., Beauloye, C., ... Balligand, J.-L. (2014). Enhanced expression of $\beta 3$-adrenoceptors in cardiac myocytes attenuates neurohormone-induced hypertrophic remodeling through nitric oxide synthase. Circulation, 129(4), 451-62. doi:10.1161/CIRCULATIONAHA.113.004940

14. Vij, M., \& Drake, M. J. (2015). Clinical use of the $\beta 3$ adrenoceptor agonist mirabegron in patients with overactive bladder syndrome. Therapeutic advances in urology, 7(5), 241-8. doi:10.1177/1756287215591763

15. Rossello, X., \& Yellon, D. M. (2016). Cardioprotection: The Disconnect Between Bench 
and Bedside. Circulation, 134(8), 574-575.

doi:10.1161/CIRCULATIONAHA.116.022829

16. Eltink, C., Lee, J., Schaddelee, M., Zhang, W., Kerbusch, V., Meijer, J., ... Sawamoto, T. (2012). Single dose pharmacokinetics and absolute bioavailability of mirabegron, a $\beta_{3}$-adrenoceptor agonist for treatment of overactive bladder. International journal of clinical pharmacology and therapeutics, 50(11), 838-50. doi:10.5414/CP201782

17. Korstanje, C., Suzuki, M., Yuno, K., Sato, S., Ukai, M., Schneidkraut, M. J., \& Yan, G. X. (2017). Translational science approach for assessment of cardiovascular effects and proarrhythmogenic potential of the beta-3 adrenergic agonist mirabegron. Journal of pharmacological and toxicological methods, 87, 74-81.

doi:10.1016/j.vascn.2017.04.008

18. Fernández-Jiménez, R., Sánchez-González, J., Agüero, J., García-Prieto, J., LópezMartín, G. J., García-Ruiz, J. M., ... Ibáñez, B. (2015). Myocardial Edema After Ischemia/Reperfusion Is Not Stable and Follows a Bimodal Pattern. Journal of the American College of Cardiology, 65(4), 315-323. doi:10.1016/j.jacc.2014.11.004

19. Kelley, K. W., Curtis, S. E., Marzan, G. T., Karara, H. M., \& Anderson, C. R. (1973). Body surface area of female swine. Journal of animal science, 36(5), 927-30.

20. Bundgaard, H., Axelsson, A., Hartvig Thomsen, J., Sørgaard, M., Kofoed, K. F., Hasselbalch, R., ... Rasmussen, H. H. (2017). The first-in-man randomized trial of a beta3 adrenoceptor agonist in chronic heart failure: the BEAT-HF trial. European journal of heart failure, 19(4), 566-575. doi:10.1002/ejhf.714

21. Gauthier, C., Rozec, B., Manoury, B., \& Balligand, J.-L. (2011). Beta-3 Adrenoceptors as New Therapeutic Targets for Cardiovascular Pathologies. Current Heart Failure Reports, 8(3), 184-192. doi:10.1007/s11897-011-0064-6

22. Takasu, T., Ukai, M., Sato, S., Matsui, T., Nagase, I., Maruyama, T., ... Yamaguchi, O. (2007). Effect of (R)-2-(2-aminothiazol-4-yl)-4'-\{2-[(2-hydroxy-2- 
phenylethyl)amino]ethyl \} acetanilide (YM178), a novel selective beta3-adrenoceptor agonist, on bladder function. The Journal of pharmacology and experimental therapeutics, 321(2), 642-7. doi:10.1124/jpet.106.115840

23. Aizawa, N., Homma, Y., \& Igawa, Y. (2012). Effects of mirabegron, a novel $\beta 3$ adrenoceptor agonist, on primary bladder afferent activity and bladder microcontractions in rats compared with the effects of oxybutynin. European urology, 62(6), 1165-73. doi:10.1016/j.eururo.2012.08.056

24. Gillespie, J. I., Palea, S., Guilloteau, V., Guerard, M., Lluel, P., \& Korstanje, C. (2012). Modulation of non-voiding activity by the muscarinergic antagonist tolterodine and the $\beta$ 3 -adrenoceptor agonist mirabegron in conscious rats with partial outflow obstruction. BJU International, 110(2b), E132-E142. doi:10.1111/j.1464-410X.2012.11240.x

25. Gauthier, C., Tavernier, G., Trochu, J. N., Leblais, V., Laurent, K., Langin, D., ... Le Marec, H. (1999). Interspecies differences in the cardiac negative inotropic effects of beta(3)-adrenoceptor agonists. The Journal of pharmacology and experimental therapeutics, 290(2), 687-93.

26. Rossello, X., Hall, A. R., Bell, R. M., \& Yellon, D. M. (2015). Characterization of the Langendorff Perfused Isolated Mouse Heart Model of Global Ischemia-Reperfusion Injury: Impact of Ischemia and Reperfusion Length on Infarct Size and LDH Release. Journal of Cardiovascular Pharmacology and Therapeutics, 21(3), 286-295. doi: $10.1177 / 1074248415604462$

27. Kleinbongard, P., Amanakis, G., Skyschally, A., \& Heusch, G. (2018). Reflection of Cardioprotection by Remote Ischemic Perconditioning in Attenuated ST-Segment Elevation During Ongoing Coronary Occlusion in Pigs: Evidence for Cardioprotection From Ischemic Injury. Circulation research, 122(8), 1102-1108. doi:10.1161/CIRCRESAHA.118.312784

28. Rossello, X., \& Ibanez, B. (2018). Infarct Size Reduction by Targeting Ischemic Injury. 
Circulation Research, 122(8), 1041-1043.

29. García-Ruiz, J. M., Fernández-Jiménez, R., García-Alvarez, A., Pizarro, G., GalánArriola, C., Fernández-Friera, L., ... Ibáñez, B. (2016). Impact of the Timing of Metoprolol Administration During STEMI on Infarct Size and Ventricular Function. Journal of the American College of Cardiology, 67(18), 2093-2104. doi:10.1016/j.jacc.2016.02.050

30. Pryds, K., Terkelsen, C. J., Sloth, A. D., Munk, K., Nielsen, S. S., Schmidt, M. R., \& Bøtker, H. E. (2016). Remote ischaemic conditioning and healthcare system delay in patients with ST-segment elevation myocardial infarction. Heart, 102(13), 1023-8. doi:10.1136/heartjnl-2015-308980

31. Dall'Armellina, E., Karia, N., Lindsay, A. C., Karamitsos, T. D., Ferreira, V., Robson, M. D., ... Choudhury, R. P. (2011). Dynamic changes of edema and late gadolinium enhancement after acute myocardial infarction and their relationship to functional recovery and salvage index. Circulation. Cardiovascular imaging, 4(3), 228-36. doi:10.1161/CIRCIMAGING.111.963421

32. Fernández-Jiménez, R., Galán-Arriola, C., Sánchez-González, J., Agüero, J., LópezMartín, G. J., Gomez-Talavera, S., ... Ibanez, B. (2017). Effect of Ischemia Duration and Protective Interventions on the Temporal Dynamics of Tissue Composition After Myocardial Infarction. Circulation research, 121(4), 439-450. doi:10.1161/CIRCRESAHA.117.310901

33. Jablonowski, R., Engblom, H., Kanski, M., Nordlund, D., Koul, S., van der Pals, J., ... Arheden, H. (2015). Contrast-Enhanced CMR Overestimates Early Myocardial Infarct Size: Mechanistic Insights Using ECV Measurements on Day 1 and Day 7. JACC. Cardiovascular imaging, 8(12), 1379-1389. doi:10.1016/j.jcmg.2015.08.015

34. Fernández-Jiménez, R., García-Prieto, J., Sánchez-González, J., Agüero, J., LópezMartín, G. J., Galán-Arriola, C., ... Ibáñez, B. (2015). Pathophysiology Underlying the 
Bimodal Edema Phenomenon After Myocardial Ischemia/Reperfusion. Journal of the American College of Cardiology, 66(7), 816-28. doi:10.1016/j.jacc.2015.06.023

35. Fernández-Jiménez, R., Barreiro-Pérez, M., Martin-García, A., Sánchez-González, J., Agüero, J., Galán-Arriola, C., ... Ibanez, B. (2017). Dynamic Edematous Response of the Human Heart to Myocardial Infarction: Implications for Assessing Myocardial Area at Risk and Salvage. Circulation, 136(14), 1288-1300.

doi:10.1161/CIRCULATIONAHA.116.025582 


\section{TABLES}

Table 1. Effect of intravenous administration of mirabegron on heart rate, mean systemic artery pressure, mean pulmonary artery pressure and cardiac output in anesthetized pigs for doses 5 .

10,50 and $500 \mu \mathrm{g} / \mathrm{Kg}$,

\begin{tabular}{|c|c|c|c|c|c|c|c|c|}
\hline & Min 1 & $\operatorname{Min} 2$ & Min 3 & $\operatorname{Min} 4$ & $\operatorname{Min} 5$ & Min 10 & Min 15 & $\operatorname{Min} 20$ \\
\hline \multicolumn{9}{|l|}{ HR } \\
\hline $5 \mu \mathrm{g} / \mathrm{Kg}$ & $0.3(0.5)$ & $4.4(0.8)$ & $2.2(0.8)$ & $1.1(0.8)$ & $-0.1(1.7)$ & $0.2(1.2)$ & $1.1(1.6)$ & $0.5(1.8)$ \\
\hline $10 \mu \mathrm{g} / \mathrm{Kg}$ & $4.8(1.0)$ & $7.1(1.5)$ & $2.9(3.1)$ & $2.1(2.8)$ & $3.2(2.0)$ & $3.5(1.3)$ & $5.0(2.1)$ & $5.2(2.4)$ \\
\hline $50 \mu \mathrm{g} / \mathrm{Kg}$ & $17.8(4.0)$ & $14.4(5.8)$ & $5.5(3.3)$ & $3.4(3.0)$ & 4.0 (1.9) & $3.1(1.4)$ & $2.4(1.7)$ & $1.8(1.7)$ \\
\hline $500 \mu \mathrm{g} / \mathrm{Kg}$ & 48.7 (5.3) & $35.9(4.3)$ & $24.5(4.7)$ & $20.4(3.8)$ & $20.8(4.1)$ & $18.4(2.1)$ & 19.8(1.7) & $17.9(1.3)$ \\
\hline \multicolumn{9}{|l|}{ SAP } \\
\hline $5 \mu \mathrm{g} / \mathrm{Kg}$ & $-4.8(0.6)$ & $-3.6(0.5)$ & $-2.1(0.8)$ & $-1.3(1.3)$ & $-0.8(1.9)$ & $-1.5(1.8)$ & $-1.0(2.2)$ & $-1.7(2.8)$ \\
\hline $10 \mu \mathrm{g} / \mathrm{Kg}$ & $-6.6(1.4)$ & $-2.0(0.9)$ & $-0.5(1.4)$ & $-0.5(1.2)$ & $-0.8(1.3)$ & $-1.4(1.3)$ & $-1.0(1.6)$ & $-1.0(1.9)$ \\
\hline $50 \mu \mathrm{g} / \mathrm{Kg}$ & $-9.2(2.5)$ & $-3.2(1.7)$ & $-0.6(1.6)$ & $0.0(1.5)$ & $-0.2(1.2)$ & $-0.8(1.0)$ & $-0.1(1.5)$ & $0.4(1.3)$ \\
\hline $500 \mu \mathrm{g} / \mathrm{Kg}$ & $-14.6(4.0)$ & $-7.9(2.6)$ & $-2.9(1.2)$ & $-3.7(1.2)$ & $-4.0(1.4)$ & $-3.1(1.2)$ & $-5.0(1.3)$ & $-4.9(1.4)$ \\
\hline \multicolumn{9}{|l|}{ PAP } \\
\hline $5 \mu \mathrm{g} / \mathrm{Kg}$ & $-1.7(2.5)$ & $-0.8(2.4)$ & $-3.7(2.6)$ & $-3.6(4.1)$ & $-3.6(4.1)$ & $-3.6(3.5)$ & $1.4(4.7)$ & $-1.6(3.4)$ \\
\hline $10 \mu \mathrm{g} / \mathrm{Kg}$ & $3.1(2.0)$ & $0.1(1.6)$ & $-1.9(1.9)$ & $-1.9(1.9)$ & $-3.9(1.6)$ & $-5.0(1.9)$ & $-1.0(1.9)$ & $-2.9(1.8)$ \\
\hline $50 \mu \mathrm{g} / \mathrm{Kg}$ & $1.3(2.5)$ & $-2.9(3.4)$ & $-4.2(3.0)$ & $-5.0(2.6)$ & $-5.7(2.9)$ & $-0.8(2.9)$ & $1.5(3.6)$ & $0.1(3.4)$ \\
\hline $500 \mu \mathrm{g} / \mathrm{Kg}$ & $-6.1(3.6)$ & $-11.6(2.9)$ & $-13.0(0.7)$ & $-13.2(2.3)$ & $-13.6(2.2)$ & $-8.5(1.7)$ & $-8.5(1.7)$ & $-9.5(1.6)$ \\
\hline \multicolumn{9}{|l|}{$\mathrm{CO}$} \\
\hline $5 \mu \mathrm{g} / \mathrm{Kg}$ & - & - & - & - & $4.1(2.5)$ & $7.5(2.0)$ & - & $4.7(3.0)$ \\
\hline $10 \mu \mathrm{g} / \mathrm{Kg}$ & - & - & - & - & $8.6(1.1)$ & $6.5(3.1)$ & - & $5.3(3.6)$ \\
\hline $50 \mu \mathrm{g} / \mathrm{Kg}$ & - & - & - & - & $4.5(3.0)$ & $5.8(1.7)$ & - & $3.0(2.4)$ \\
\hline $500 \mu \mathrm{g} / \mathrm{Kg}$ & - & - & - & - & $9.6(5.5)$ & $12.5(5.7)$ & - & $13.1(3.1)$ \\
\hline
\end{tabular}

Results are expressed as percentage of change with respect the baseline value before drug administration (SD in brackets)

HR heart rate (bpm); SAP, mean systemic arterial pressure (mmHg); PAP, mean pulmonary artery pressure $(\mathrm{mmHg}) ; \mathrm{CO}$, cardiac output $(\mathrm{L} / \mathrm{min})$. 
Table 2. Differences in hemodynamic parameters between groups during the administration of either placebo or mirabegron in the ongoing AMI

\begin{tabular}{|l|c|c|c|c|}
\hline & \multicolumn{2}{|c|}{$\begin{array}{c}\text { Mean systemic arterial } \\
\text { pressure (mm Hg) }\end{array}$} & \multicolumn{2}{|c|}{ Heart rate (bpm) } \\
\hline Min & Mirabegron & Placebo & Mirabegron & Placebo \\
\hline $40^{\text {a }}$ & $65(8)$ & $70(11)$ & $80(14)$ & $97(21)$ \\
\hline 41 & $65(9)$ & $67(10)$ & $79(13)$ & $91(19)$ \\
\hline 42 & $63(8)$ & $65(9)$ & $79(13)$ & $92(17)$ \\
\hline 43 & $61(8)$ & $64(8)$ & $80(14)$ & $93(15)$ \\
\hline 44 & $64(8)$ & $68(12)$ & $83(10)$ & $95(14)$ \\
\hline $45^{\text {b }}$ & $68(11)$ & $70(11)$ & $83(17)$ & $94(15)$ \\
\hline
\end{tabular}

a Just before mirabegron administration

${ }^{\mathrm{b}}$ Just before reperfusion

Values are expressed as mean (SD). Comparisons between different time points within and between treatment groups were all non-significant ( $n=10 /$ group). 
Table 3. CMR results at day 7

\begin{tabular}{|l|c|c|c|}
\hline & Mirabegron (N=10) & Placebo (N=10) & p value \\
\hline LV mass $\left(\mathrm{g} / \mathrm{m}^{2}\right)$ & $86.6(14.0)$ & $83.2(7.8)$ & 0.524 \\
\hline LVEDV $\left(\mathrm{ml} / \mathrm{m}^{2}\right)$ & $165.9(3.9)$ & $172.0(23.8)$ & 0.481 \\
\hline LVESV $\left(\mathrm{ml} / \mathrm{m}^{2}\right)$ & $105.7(10.2)$ & $113.3(23.8)$ & 0.370 \\
\hline LVEF $(\%)$ & $36.3(3.3)$ & $34.6(5.7)$ & 0.430 \\
\hline Edema (g) & $27.1(6.1)$ & $28.4(6.8)$ & 0.659 \\
\hline Edema (\%LV) & $38.0(5.6)$ & $38.4(5.9)$ & 0.884 \\
\hline IS (g) & $24.2(6.2)$ & $25.2(7.1)$ & 0.763 \\
\hline IS (\%LV) & $35.0(6.0)$ & $35.9(7.1)$ & 0.782 \\
\hline MVO (g) & $2.3(1.6)$ & $2.1(1.9)$ & 0.841 \\
\hline
\end{tabular}

LV mass and volumes are normalized by body surface area.

LV, left ventricular; LVEDV, left ventricular end-diastolic volume; LVEF, left ventricular ejection fraction; LVESV, left ventricular end-systolic volume; IS, infarct size; MVO, microvascular obstruction 
Table 4. CMR results at day 45

\begin{tabular}{|l|c|c|c|}
\hline & Mirabegron (N=8) & Placebo (N=10) & p value \\
\hline LV mass $(\mathrm{g})$ & $72.7(8.0)$ & $75.5(10.7)$ & 0.554 \\
\hline LVEDV $\left(\mathrm{ml} / \mathrm{m}^{2}\right)$ & $189.6(23.7)$ & $202.9(43.4)$ & 0.449 \\
\hline LVESV $\left(\mathrm{ml} / \mathrm{m}^{2}\right)$ & $127.9(26.7)$ & $143.9(43.5)$ & 0.377 \\
\hline LVEF $(\%)$ & $33.1(5.7)$ & $30.0(7.0)$ & 0.366 \\
\hline IS $(\mathrm{g})$ & $18.1(5.0)$ & $21.6(7.6)$ & 0.300 \\
\hline IS $(\% \mathrm{LV})$ & $23.7(6.3)$ & $25.2(4.5)$ & 0.581 \\
\hline
\end{tabular}

LV mass and volumes are normalized by body surface area.

LV, left ventricular; LVEDV, left ventricular end-diastolic volume; LVEF, left ventricular ejection fraction; LVESV, left ventricular end-systolic volume; IS, infarct size. 


\section{FIGURE LEGENDS}

Fig 1. Short-term cardioprotective effect in pigs subjected to ischemia/reperfusion injury after pre-reperfusion administration of the $\beta 3 \mathrm{AR}$ mirabegron: infarct size (a) and left ventricular ejection fraction (b) at day 7

a

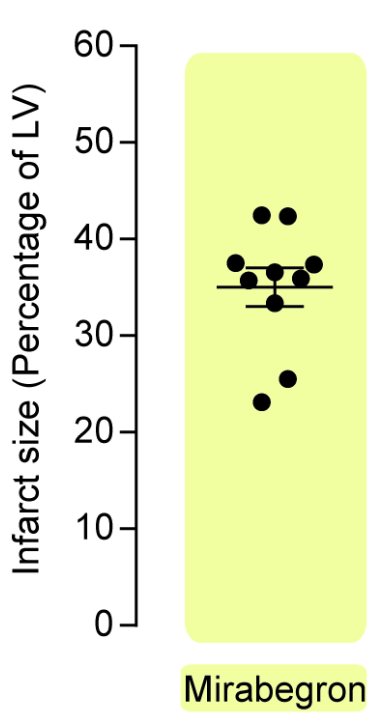

ns

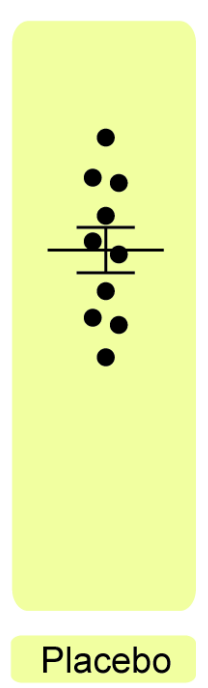

b

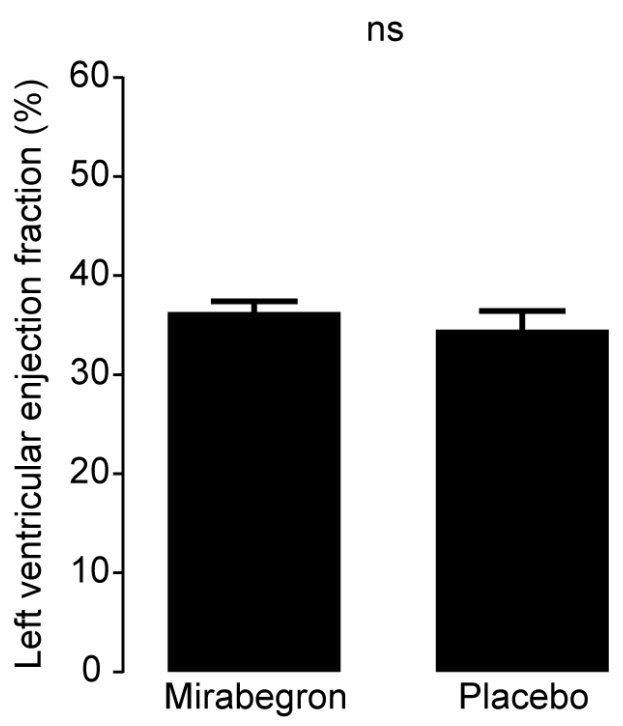

For panel a: black lines represent mean and SEM for infarct size (\%) and circles represent individual animal data. For panel b: bar graphs represent mean and SEM for left ventricular ejection fraction (\%). LV, left ventricle; ns, non-significant. 
Fig 2. Long-term cardioprotective effect in pigs subjected to ischemia/reperfusion injury after pre-reperfusion administration of the $\beta 3 \mathrm{AR}$ mirabegron: infarct size (a) and left ventricular ejection fraction (b) at day 45

a

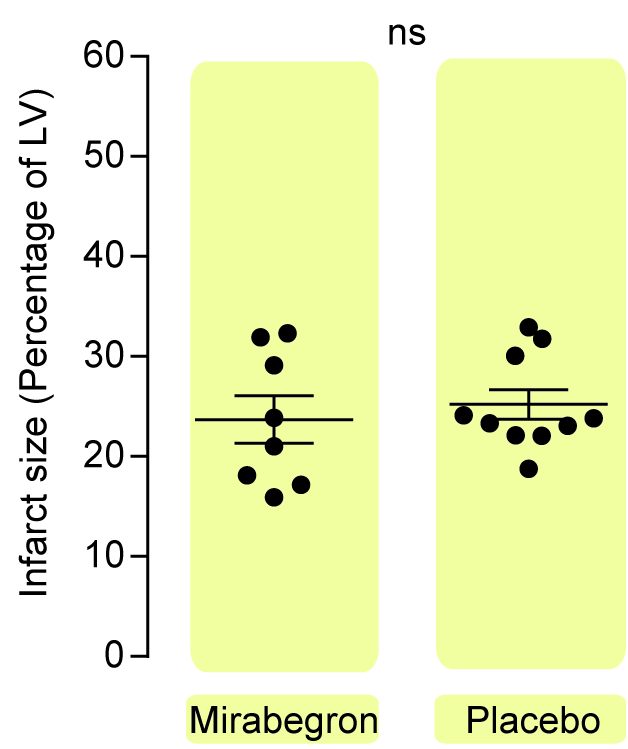

b

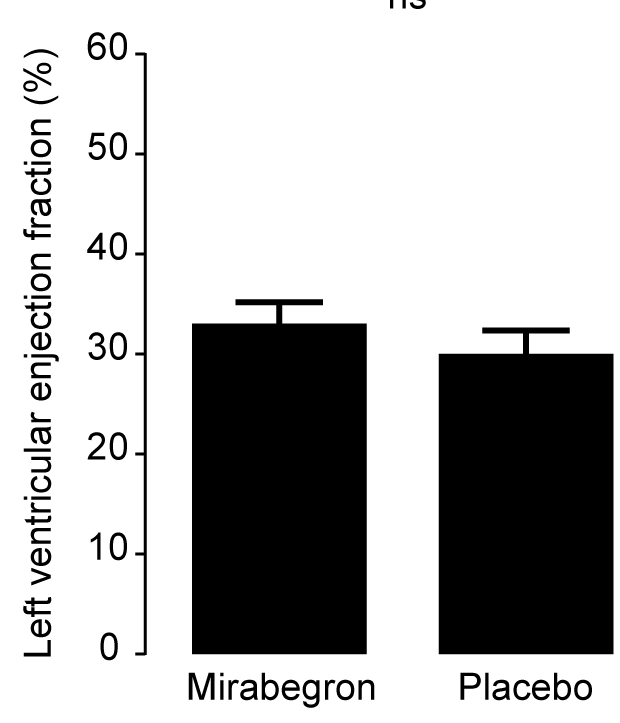

For panel a: black lines represent mean and SEM for infarct size (\%) and circles represent individual animal data. For panel b: bar graphs represent mean and SEM for left ventricular ejection fraction (\%). LV, left ventricle; ns, non-significant. 